\title{
Engineering a diaphorase via directed evolution for enzymatic biofuel cell application
}

\author{
Chunling Ma', Meixia Liu' ${ }^{1,2}$, Chun You ${ }^{1,2}$ and Zhiguang Zhu ${ }^{1,2^{*}}$ (i)
}

\begin{abstract}
Background: Diaphorase (DI) has received wide attention as the key anodic enzyme mediating the electron transfer and electric energy generation in enzymatic biofuel cells (EBFCs). Lowering the anodic pH may be a useful strategy for constructing high-performance in EBFCs. However, most DI suffered from the poor activity at low pHs. Therefore, it is necessary to modify the activity and its acidic tolerance to further improve the performance of the EBFC.

Results: This paper attempts to improve the enzyme activity of DI originated from Geobacillus stearothermophilus under acidic conditions through directed evolution. Three rounds of random mutagenesis by error-prone PCR of the GsDI gene followed by high-throughput screening allowed the identification of the mutant 3-8 (H37Q, S73T, F105L, S68T, G61S, D74V) exhibiting a 4- or 7-fold increase in the catalytic activity at pH 5.4 or 4.5 compared to that of the wild type. And the pH stability of mutant 3-8 was significantly better than that of wild type and showed a 1.3 times higher in the stability at $\mathrm{pH}$ 5.4. The EBFC anode equipped with $0.5 \mathrm{mg}$ of mutant $3-8$ achieved a maximum current of $40 \mu \mathrm{A}$ at pH 5.4, much higher than that with the same loading of the wild type enzyme.

Conclusion: The GsDI has been improved in the specific activity and pH stability by directed evolution which leads to the improvement of the EBFC performance. Also, the enlarged catalytic channel of mutant and decreased B-factor may be beneficial for the activity and stability. These results suggest that this engineered DI will be a useful candidate for the construction of enhanced EBFCs.
\end{abstract}

Keywords: Diaphorase, Enzyme engineering, Directed evolution, Enzymatic biofuel cell, Bioelectrocatalysis

\section{Introduction}

Diaphorase (DI) is a type of flavin mononucleotide (FMN)-bound enzymes that catalyze the reduction of various dyes, such as methylene blue, resazurin, vitamin $\mathrm{K}_{3}\left(\mathrm{VK}_{3}\right)$, and azo dyes, which act as hydrogen acceptors from the reduced form of nicotinamide adenine dinucleotide (phosphate), i.e., NAD(P)H (Matsumoto et al. 2010; Rice et al. 1998; Shoji et al. 2016; Zhu et al. 2014). It can also be named as NAD(P)H dehydrogenase (EC 1.6.99.1). Because an oxidized FMN-DI has a strong absorbance at $452 \mathrm{~nm}$ and can be reduced to a $\mathrm{FMNH}_{2}$-DI by accepting

\footnotetext{
${ }^{*}$ Correspondence: zhu_zg@tib.cas.cn

${ }^{1}$ Tianjin Institute of Industrial Biotechnology, Chinese Academy of Sciences, 32 West 7th Avenue, Tianjin Airport Economic Area, Tianjin 300308, People's Republic of China

Full list of author information is available at the end of the article
}

two electrons, it has been mainly applied to the coupled colorimetric determination of numerous dehydrogenase-mediated reactions (Collins et al. 2016). Since that the first DI was purified from mammalian heart muscle, many DIs have been obtained from various bacteria including Thermotoga maritima, Geobacillus stearothermophilus, Bacillus subtilis and Clostridium kluyveri (Bergsma et al. 1982; Kim and Kim 2018; Shoji et al. 2016; Zhu and Zhang 2017).

Recently, DI has also received wide attention as the key enzyme mediating the electron transfer and electric energy generation in enzymatic biofuel cells (EBFCs). EBFC is a device that generates electricity by oxidizing fuels at the anode and reducing oxygen at the cathode via enzymatic biocatalysis (Xiao et al. 2019). Due to its high safety, good biocompatibility, and the use of 
renewable biocatalysts and high-density fuels, EBFC is believed to hold the promise as a next generation millior micro-power source for wearable and implantable electronic devices in the future (Barton et al. 2004; Davis and Higson 2007; Mano et al. 2003). In EBFCs, the key step for electricity generation is the oxidation catalyzed by various oxidases or dehydrogenases at the anode (Kang et al. 2019; Kim et al. 2013; Liang et al. 2012; Scheiblbrandner and Ludwig 2019). Among such enzymes, NAD-dependent dehydrogenases account for a great portion. Many fuels such as glucose, xylose, formate, and glucose 6-phosphate (G6P), rely on their respective dehydrogenase to be oxidized, coupled with NADH regeneration catalyzed by DI (Gai et al. 2015; Wu et al. 2018; Zhu and Zhang 2017). For example, in our system, G6P as the fuel is oxidized by two enzymes, G6P dehydrogenase $(\mathrm{G} 6 \mathrm{PDH})$ and 6-phosphogluconate dehydrogenase (6PGDH). The NADH generated from NAD is further oxidized by DI, along with the electron transfer from $\mathrm{NADH}$ to the mediator, $\mathrm{VK}_{3}$, which is then oxidized at the anode and releases electrons. DI plays a vital role in this system in bridging the biological electron carrier, NAD, and the electrode, and mitigating the electron transfer potential barrier between them.

So far, there have been tremendous efforts focusing on improving the performance of EBFCs (e.g., power output and lifetime) and broadening their applications, such as constructing novel 3-dimensional nanomaterials for bioelectrodes, utilizing highly stable enzymes and biomimetic cofactors, as well as optimizing electrolyte composition and concentration (Campbell et al. 2012; Chen et al. 2016; Sakai et al. 2009). In our previous study, we demonstrated that lowering anodic $\mathrm{pH}$ may be a useful strategy for constructing high-performance in EBFCs, as the proton concentration at the lowered $\mathrm{pH}$ can be significantly increased at the anode and it therefore provided a high proton transport driving force (Ma et al. 2019). However, the DI used was derived from G. stearothermophilus with an optimum $\mathrm{pH}$ at 7.3 and still suffered from the poor activity at low $\mathrm{pHs}$, severely limiting the long-term operation of the EBFC. Therefore, to further improve the performance of our EBFC, it is desirable to engineer this rate- and stability-limiting GsDI and increase its acidic tolerance.

Directed evolution is a powerful method for engineering of biological systems including proteins, pathways and genomes for various applications (Denard et al. 2015; Yang et al. 2019). In the EBFC field, the catalytic turnover and binding affinity of glucose oxidase have been tuned via directed evolution in order to achieve the fast oxidation of glucose (Mano 2019; Yu et al. 2011; Zhu et al. 2007). Alternatively, laccase has been directed evolved for improved catalytic activity, tailored substrate specificity, and enhanced tolerance to alkaline conditions
(Camarero et al. 2012; Monza et al. 2015; Novoa et al. 2019). Recently, a DI has been engineered to increase its reactivity against a specific mediator, 2-amino-1,4-naphthoquinone, aiming to improve the power output of the EBFC (Sugiyama et al. 2010). A 6PGDH has been directed evolved toward increased acid-tolerance so that the operation conditions of the EBFC can be broadened (Ma et al. 2019).

In this study, the development of an acid-tolerant DI for the EBFC application is reported. The directed evolution method based on a colorimetric screening of DI variants has been developed. Three rounds of evolution bring us with the best mutant exhibiting a significantly increased activity and stability at the reduced $\mathrm{pH}$. The improved electrochemical performance of the EBFC constructed is also observed.

\section{Materials and methods Materials}

The primers were synthesized from GENEWIZ (Beijing, P.R. China). Taq DNA polymerase and PrimeSTAR Max DNA polymerase were purchased from TaKaRa (Dalian, P.R. China). Other enzymes for molecular biology experiments were purchased from New England Biolabs (Ipswich, MA, U. S.). E. coli Top10 was used for gene cloning and recombinant protein expression. Tetra-nitro blue tetrazolium (TNBT) was purchased from Solarbio (Beijing, P. R. China). Nicotinamide adenine dinucleotide $\left(\mathrm{NAD}^{+}\right)$and glucose 6-phosphate (G6P) were purchased from Sigma-Aldrich (St. Louis, MO, U. S.).

\section{Random mutagenesis and library creation}

The plasmid pET28a-Ptac-di was used as template for variant library generation by error-prone PCR with a pair of primers DI_F/DI_R. The sequences were 5'-TTAAC TTTAA GAAGG AGATA TACAT ATGAC GAAAG TATTG TACAT CACCG-3' ${ }^{\prime}$ and $5^{\prime}$-TCAGT GGTGG TGGTG GTGGT GCTCG AGAAA CGTGT GCGCC AAGTC TTTCG-3'. The reaction solution with a total volume of $50 \mu \mathrm{L}$ contained $0.2 \mathrm{mM}$ dATP, $0.2 \mathrm{mM}$ dGTP, $1 \mathrm{mM}$ dCTP, $1 \mathrm{mM}$ dTTP, $5 \mathrm{mM} \mathrm{MgCl}_{2}, 0.01 \mathrm{mM}$ $\mathrm{MnCl}_{2}, 0.05 \mathrm{U} / \mu \mathrm{L}$ the Taq polymerase and $0.4 \mu \mathrm{M}$ primer pairs. The PCR reaction was performed under the following conditions: initial denaturation at $94{ }^{\circ} \mathrm{C}$ for $2 \mathrm{~min}$, followed by 18 consecutive cycles of denaturation at $94{ }^{\circ} \mathrm{C}$ for $30 \mathrm{~s}$, anneal at $58{ }^{\circ} \mathrm{C}$ for $20 \mathrm{~s}$, extension at $72{ }^{\circ} \mathrm{C}$ for $30 \mathrm{~s}$, and a final extension at $72{ }^{\circ} \mathrm{C}$ for $5 \mathrm{~min}$. The $50 \mu \mathrm{L}$ reaction solution of the vector backbone was amplified from pET28a-Ptac-di with $25 \mu \mathrm{L}$ PrimeSTAR Max and $0.4 \mu \mathrm{M}$ primer pairs vector_F/vector_R. The sequences were 5'-CGAAA GACTT GGCGC ACACG TTTCT CGAGC ACCAC CACCA CCACC ACTGA-3'; 5'-CGGTG ATGTA CAATA CTTTC GTCAT ATGTA 
TATCT CCTTC TTAAA GTTAA-3', respectively. The PCR conditions were initial denaturation at $98{ }^{\circ} \mathrm{C}$ for $2 \mathrm{~min}, 30$ cycles of denaturation at $98{ }^{\circ} \mathrm{C}$ for $20 \mathrm{~s}$, annealing at $58^{\circ} \mathrm{C}$ for $30 \mathrm{~s}$ and extension at $72^{\circ} \mathrm{C}$ for $3 \mathrm{~min}$, and a final extension at $72{ }^{\circ} \mathrm{C}$ for $5 \mathrm{~min}$. The two PCR products were digested by DpnI at $37^{\circ} \mathrm{C}$ for $1 \mathrm{~h}$ and purified through DNA purification kit (Tiangen, Beijing, P. R. China).

The two purified PCR products were assembled into DNA multimers by prolonged overlap extension PCR (POE-PCR). The $50-\mu \mathrm{L}$ reaction solution comprised $1 \mathrm{ng} /$ $\mu \mathrm{L}$ mutated di PCR product; $9 \mathrm{ng} / \mu \mathrm{L}$ linearized vector backbone (equimolar with the mutated di PCR product) and $25 \mu \mathrm{L}$ Prime STAR Max. POE-PCR conditions were similar to the vector backbone. Approximately $100 \mu \mathrm{L}$ of the POE-PCR product was digested in $150-\mu \mathrm{L}$ reaction solution with 40 units of XhoI at $37^{\circ} \mathrm{C}$ for $24 \mathrm{~h}$. The linearized plasmid was then purified, ligated and transformed into E. coli Top10 competent cell for screening as previously described (You et al. 2012). The protein with a C-terminal His-tag was convenient for purification.

Screening of the mutants with high activity at lowered pHs The double-layer-based TNBT screening method was carried out as previously described with some modifications (Fig. 1a) (Ma et al. 2019). Transformed cells containing mutant plasmid libraries were firstly incubated on the LB kanamycin agar plate at $37{ }^{\circ} \mathrm{C}$ for $16 \mathrm{~h}$. Then, the colonies were treated at $70{ }^{\circ} \mathrm{C}$ for $1 \mathrm{~h}$ to lyse the cell. When the plate temperature dropped to the room temperature, $5 \mathrm{~mL}$ of reagent solution constituted of $0.5 \%$ melted agarose solution, $0.1 \mathrm{mM}$ NADH, $50 \mu \mathrm{M}$ TNBT, and $100 \mathrm{mM}$ acetate $(\mathrm{pH} 4.5)$ was poured on the treated colonies. After incubating at room temperature for $30 \mathrm{~min}$, the mutants of GsDI were identified based on the formation of black color (Fig. 1b). The plasmids of isolated colonies were then extracted by mini plasmid kit (Tiangen, Beijing, P. R. China) and transformed into Top10 for DNA sequencing and protein overexpression.

\section{Protein expression and purification}

The Top10 strains harboring plasmids encoding the GsDI wild type and its mutants were grown in LB medium containing $50 \mu \mathrm{g} / \mathrm{ml}$ kanamycin at $37{ }^{\circ} \mathrm{C}$ and induced by adding $0.1 \mathrm{mM}$ IPTG when the absorbance of the $\mathrm{OD}_{600}$ reached $0.8-1.0$, and the culture was incubated at $18{ }^{\circ} \mathrm{C}$ for $16 \mathrm{~h}$. Cells were harvested by centrifugation and then were resuspended in $20 \mathrm{mM}$ 4-(2-hydroxyethyl)1-piperazineethanesulfonic acid (HEPES) buffer ( $\mathrm{pH} 7.5)$ containing $50 \mathrm{mM} \mathrm{NaCl}$. After sonication and centrifugation, about $0.1 \mathrm{mM} F M N$ was added into the supernatant for GsDI purification. And the His-tagged protein in the supernatant was loaded onto the column packed with
HisPur Ni-NTA Resin (General Electric, NY, U. S.). Purified GsDI wild type and variants were analyzed by SDSPAGE and used for enzymatic assay. The concentration of protein was determined by the Bradford assay using bovine serum albumin (BSA) as the standard.

\section{Activity assays}

The activity of DI was evaluated at $25{ }^{\circ} \mathrm{C}$ in $100 \mathrm{mM}$ HEPES buffer ( $\mathrm{pH} 7.3$ ) or $100 \mathrm{mM}$ sodium acetate buffer (pH 5.4 or 4.5) where $0.5 \mathrm{mM} \mathrm{VK}_{3}$ was reduced by $1 \mathrm{mM}$ $\mathrm{NADH}$. One unit of reduction activity was defined as the amount of enzyme required to consume $1 \mu \mathrm{mol}$ $\mathrm{NADH}$ per minute. The decrease in the absorbance band of NADH at $340 \mathrm{~nm}$ was measured by a UV-Vis spectroscopy.

\section{Optimum $\mathrm{pH}$ and acid-tolerance}

The optimal $\mathrm{pH}$ was determined in $100 \mathrm{mM}$ acetate buffers ( $\mathrm{pH}$ 4.0-6.0), $100 \mathrm{mM}$ HEPES buffers ( $\mathrm{pH}$ 6.0-8.0), or $100 \mathrm{mM}$ Tris- $\mathrm{HCl}$ buffers ( $\mathrm{pH} 8.0-10.0)$. To evaluate the acid stability or thermostability, enzyme solutions $(100 \mathrm{mg} / \mathrm{L})$ were incubated at $25^{\circ} \mathrm{C}$ in $100 \mathrm{mM}$ sodium acetate buffer (pH 5.4) or 100 mM HEPES buffer ( $\mathrm{pH} 7.3$ ) at $60{ }^{\circ} \mathrm{C}$ for different hours, and at fixed time intervals, sample aliquots were tested for activity measurement at $25^{\circ} \mathrm{C}$ in $100 \mathrm{mM}$ HEPES buffer (pH 7.3). Three parallel experiments were performed to obtain the standard deviation.

\section{Circular dichroism measurements}

Far-UV circular dichroism (CD) measurements in the 190-260 nm region were performed on a Chirascan spectropolarimeter in a quartz cuvette cell with $0.1 \mathrm{~cm}$ path length at room temperature. The proteins were diluted in $5 \mathrm{mM}$ acetate buffers ( $\mathrm{pH} 5.0-6.0$ ) or $2.5 \mathrm{mM}$ HEPES buffers ( $\mathrm{pH} \mathrm{7.3),} \mathrm{to} \mathrm{a} \mathrm{concentration} \mathrm{of} 0.2 \mathrm{mg} /$ $\mathrm{mL}$. The spectra presented are an average from triplicate measurements. Baseline correction was carried out with the appropriate blank (buffer) during the complete collection time.

\section{Homology model analysis and reverse mutation}

The three-dimensional homology model of GsDI wild type and mutant 3-8 were made by SWISS-MODEL based on the crystal structure of Bacillus sp. FMNdependent NADH-azoreductase (PDB 3w7a, 57\% sequence identity) (Yu et al. 2014). Structures were visualized using the PyMOL Molecular Graphics System (Schrödinger, NY, U. S.). The site-directed mutagenesis of mutant 3-8 was used to reverse 6 mutation sites to their original amino acid residues to determine whether mutated amino acids had the impact on activity and acidic stability. The reverse mutation was operated with 
a

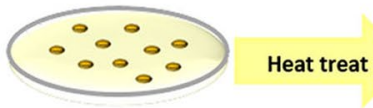

Colonies grow

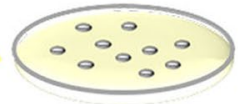

Dead cell

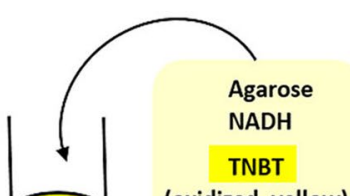

(oxidized, yellow)

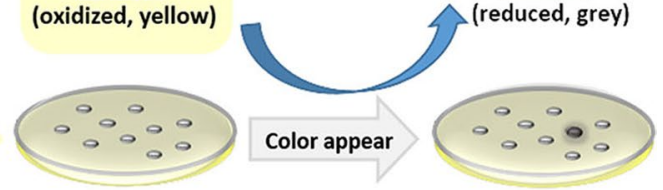

Double-layer plate
Selected colonies

b

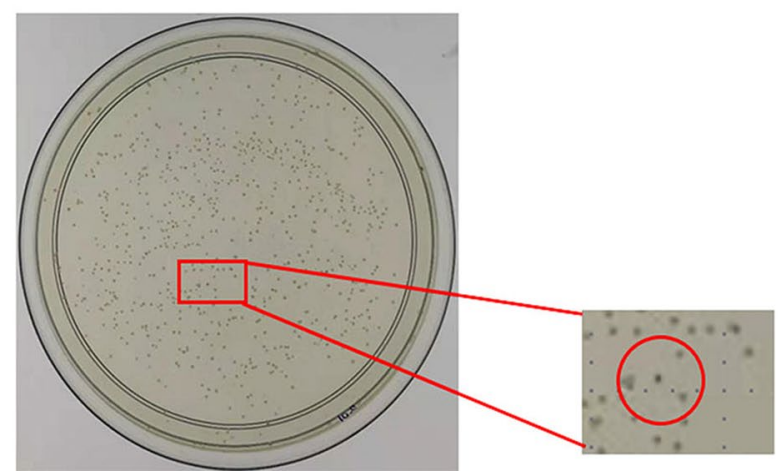

Fig. 1 a Schematic of the Petri-dish-based double-layer screening method for the fast identification of GsDI mutants and $\mathbf{b}$ the photo of a typical screening plate where positive mutants with dark grey color can be identified

a pair of primers that are $39 \mathrm{bp}$ completely reversed complementary base sequence of original amino acid residues. All primers used in this study for the reverse mutation are listed in Table 1.

\section{Electrochemical measurement}

Cyclic voltammetry was performed by a CHI 1000C potentiostat ( $\mathrm{CH}$ Instruments Inc., Shanghai, P. R. China) at $25^{\circ} \mathrm{C}$ at a scan rate $10 \mathrm{mV} / \mathrm{s}$. A three-electrode system was used for $\mathrm{CV}$ with a glassy carbon working electrode, a $\mathrm{Ag} / \mathrm{AgCl}$ reference electrode, and a Pt wire counter electrode. The same loading amount $(0.1 \mathrm{mg}$ or $0.5 \mathrm{mg})$ of GsDI wild type and mutant $3-8$ was used at $25{ }^{\circ} \mathrm{C}$ in $100 \mathrm{mM}$ sodium acetate (pH 5.4) in order to demonstrate the improved performance of the EBFC at the lowered $\mathrm{pH}$.

\section{Results and discussion}

\section{Library construction and screening}

In this study, directed evolution was used to improve the specific activity of the DI at lowered pHs. Error-prone PCR was employed in an attempt to generate the random mutant libraries of GsDI with an estimated average of one to three mutations per round. As an efficient
Table 1 The plasmids and primers used for reverse mutation

\begin{tabular}{|c|c|}
\hline Description & Contents \\
\hline Plasmids & GsDI mutant 3-8 \\
\hline \multicolumn{2}{|l|}{ Primers } \\
\hline $37-F$ & AACAAGTGCATCCGGACCATGAGGTGATCCATCTCGATT \\
\hline $37-\mathrm{R}$ & AATCGAGATGGATCACCTCATGGTCCGGATGCACTTGTT \\
\hline $61-\mathrm{F}$ & CGACGTGTTCAGCGGCTGGGGCAAACTTCGCTCCGGGAA \\
\hline $61-\mathrm{R}$ & TTCCCGGAGCGAAGTTTGCCCCAGCCGCTGAACACGTCG \\
\hline $68-\mathrm{F}$ & CAAACTTCGCTCCGGGAAATCGTTTGAAGAGCTGACTGT \\
\hline $68-\mathrm{R}$ & ACAGTCAGCTCTTCAAACGATTTCCCGGAGCGAAGTTTG \\
\hline $73-\mathrm{F}$ & GAAAACGTTTGAAGAGCTGTCTGTCGAAGAAAAAGCGAA \\
\hline $73-\mathrm{R}$ & TTCGCTTTTTCTTCGACAGACAGCTCTTCAAACGTTTTC \\
\hline $74-\mathrm{F}$ & ACGTTTGAAGAGCTGACTGACGAAGAAAAAGCGAAAGTC \\
\hline $74-\mathrm{R}$ & GACTTTCGCTTTTTTCTTCGTCAGTCAGCTCTTCAAACGT \\
\hline $105-\mathrm{F}$ & CGTCACGCCGATGTGGAACTTTTCGTTCCCGCCGGTGTT \\
\hline $105-\mathrm{R}$ & AACACCGGCGGGAACGAAAAGTTCCACATCGGCGTGACG \\
\hline
\end{tabular}

high-throughput screening method a sensitive mediator tetra-nitro blue tetrazolium (TNBT) was applied to identify positive mutant enzymes in this work. The scheme of Petri-dish-based double-layer screening method was 
shown as follows: the first layer strain was grown at $37^{\circ} \mathrm{C}$ for $16 \mathrm{~h}$, and then, the colonies were treated at $70{ }^{\circ} \mathrm{C}$ for $1 \mathrm{~h}$ to lyse the cell, degrading reduced coenzymes and deactivating the mesophilic redox enzymes, such as $E$. coli NADH dehydrogenase or thermal labile GsDI. The second agarose layer containing NADH and TNBT was incubated at room temperature. In fact, TNBT was used in many directed evolution experiment as a sensitive and stable dye (Deimann et al. 1981; Kaewarsa et al. 2017; Shen et al. 2017). Only active stable mutants could reduce the oxidized colorless TNBT to the dark grey color TNBT-formazan (Fig. 1a). As the result, the color density of colonies was closely correlated with residual activity of mutants after heat treatment. Positive mutants with deeper black colors were identified easily for the following plasmid extraction and transformation (Fig. 1b). Three rounds of screening were performed in total, with a stepwise $\mathrm{pH}$ drop finally to 4.5. Approximate 20,000 mutants were screened per round with 10-20 mutants exhibiting deeper black colors identified. Finally, positive mutants 1-8 (H37Q, S73T, F105L), 2-12 (H37Q, S73T, F105L, S68T), 3-8 (H37Q, S73T, F105L, S68T, G61S, $\mathrm{D} 74 \mathrm{~V})$ were selected for detailed characterization.

\section{Specific activity of the wild type and mutants}

The corresponding mutation sites, specific activities at different $\mathrm{pHs}$ of GsDI wild type and three selected mutants were summarized (Table 2). Remarkably, a new mutant 3-8 yielded a 4-fold increase in the activity at $\mathrm{pH}$ $5.4(0.96 \pm 0.12 \mathrm{U} / \mathrm{mg})$ and a 7 -fold enhanced activity at $\mathrm{pH} 4.5(0.61 \pm 0.1 \mathrm{U} / \mathrm{mg})$ compared to wild type. To identify possible reasons for the increased performance of

Table 2 The specific activity (U/mg) of GsDI wild type and the mutants at different pHs

\begin{tabular}{llll}
\hline Enzymes & $\begin{array}{l}\text { New mutations based on wild } \\
\text { type }\end{array}$ & pH 5.4 & pH 4.5 \\
\hline Wild type & - & $0.25 \pm 0.04$ & $0.09 \pm 0.01$ \\
M 1-8 & H37Q, S73T, F105L & $0.44 \pm 0.01$ & $0.26 \pm 0.04$ \\
M 2-12 & H37Q, S73T, F105L, S68T & $0.80 \pm 0.06$ & $0.44 \pm 0.06$ \\
M 3-8 & H37Q, S73T, F105L, S68T, G61S, & $0.96 \pm 0.12$ & $0.61 \pm 0.10$ \\
& D74V & & \\
\hline
\end{tabular}

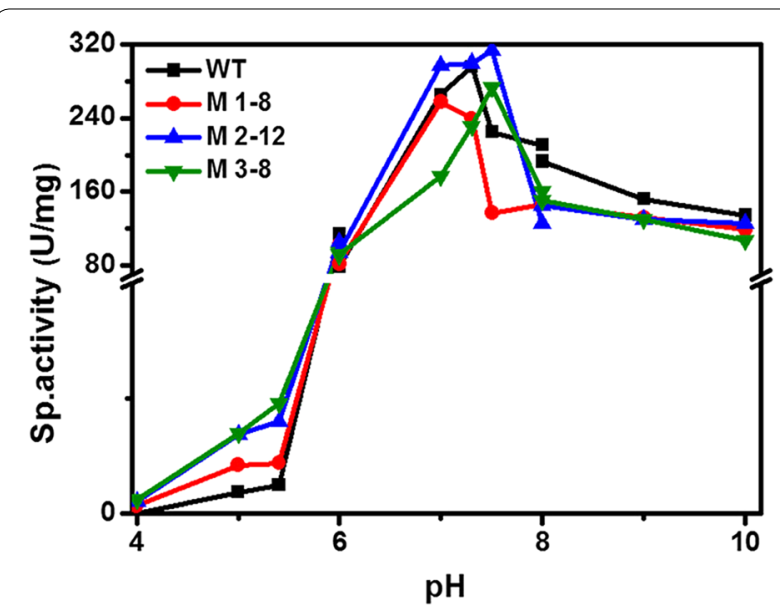

Fig. 2 The optimum $\mathrm{pH}$ of GsDI wild type and the mutants. Black line: WT; red line: mutant 1-8; blue line: mutant 2-12; green line: mutant 3-8

the mutant $3-8$, reverse mutation was conducted for six mutation sites of $3-8$.

It suggested that the sites had different effects on the activity, among which F105L had the greatest impact on the enzyme activity, as the activity of this reversed mutant dropped to $0.16 \pm 0.02 \mathrm{U} / \mathrm{mg}$ while others were only slightly decreased (Table 3 ). The site-saturation mutagenesis of F105 was performed, while no better mutation was found other than F105L (data not shown).

\section{Optimum $\mathrm{pH}$ and stability of the wild type and mutants}

The relative $\mathrm{pH}$ profile of wild type and its mutants was obtained by using $100 \mathrm{mM}$ different buffers for appropriate pHs. The optimal pHs of wild type, mutants $1-8,2-12,3-8$ were found to be $7.3,7.0,7.5$ and 7.5 , respectively (Fig. 2). Through three rounds of the random mutagenesis, the optimal $\mathrm{pH}$ seemed to be similar, probably because the mutant site that plays the main role does not involve charged amino acids. Further, the acid-tolerance of the mutants was evaluated. The $\mathrm{pH}$ stability of mutant 3-8 was significantly better than that of wild type and showed a 1.3 times higher in the stability at $\mathrm{pH} 5.4$, allowing us to operate the EBFC with a long time. In fact, all three selected mutants exhibited an improved stability as compared to the wild type

Table 3 The activity of reverse amino acid residue

\begin{tabular}{|c|c|c|c|c|c|c|c|}
\hline \multirow[t]{2}{*}{ Site } & \multicolumn{7}{|c|}{ Reverse amino acid residue } \\
\hline & 37 & 61 & 68 & 73 & 74 & 105 & M 3-8 \\
\hline Sp.act $\left(\cup \mathrm{mg}^{-1}\right)$ & $0.59 \pm 0.05$ & $0.44 \pm 0.05$ & $0.50 \pm 0.06$ & $0.59 \pm 0.09$ & $0.47 \pm 0.02$ & $0.16 \pm 0.02$ & $0.61 \pm 0.1$ \\
\hline
\end{tabular}

Enzyme activity assayed at $\mathrm{pH} 4.5$ 

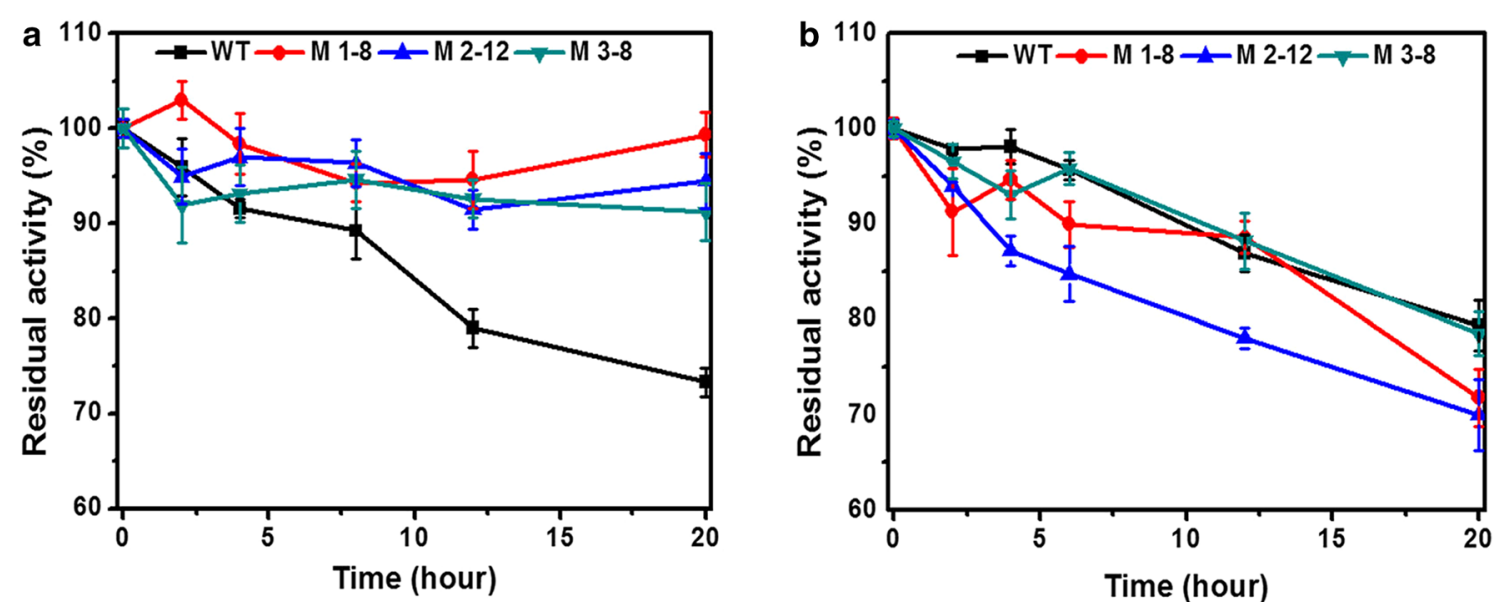

Fig. 3 The residual activity of GsDI wild type and the mutants at a pH 5.4 and the room temperature and at $\mathbf{b} 60^{\circ} \mathrm{C}$ and pH 7.3. Black line: WT; red line: mutant 1-8; blue line: mutant 2-12; green line: mutant 3-8
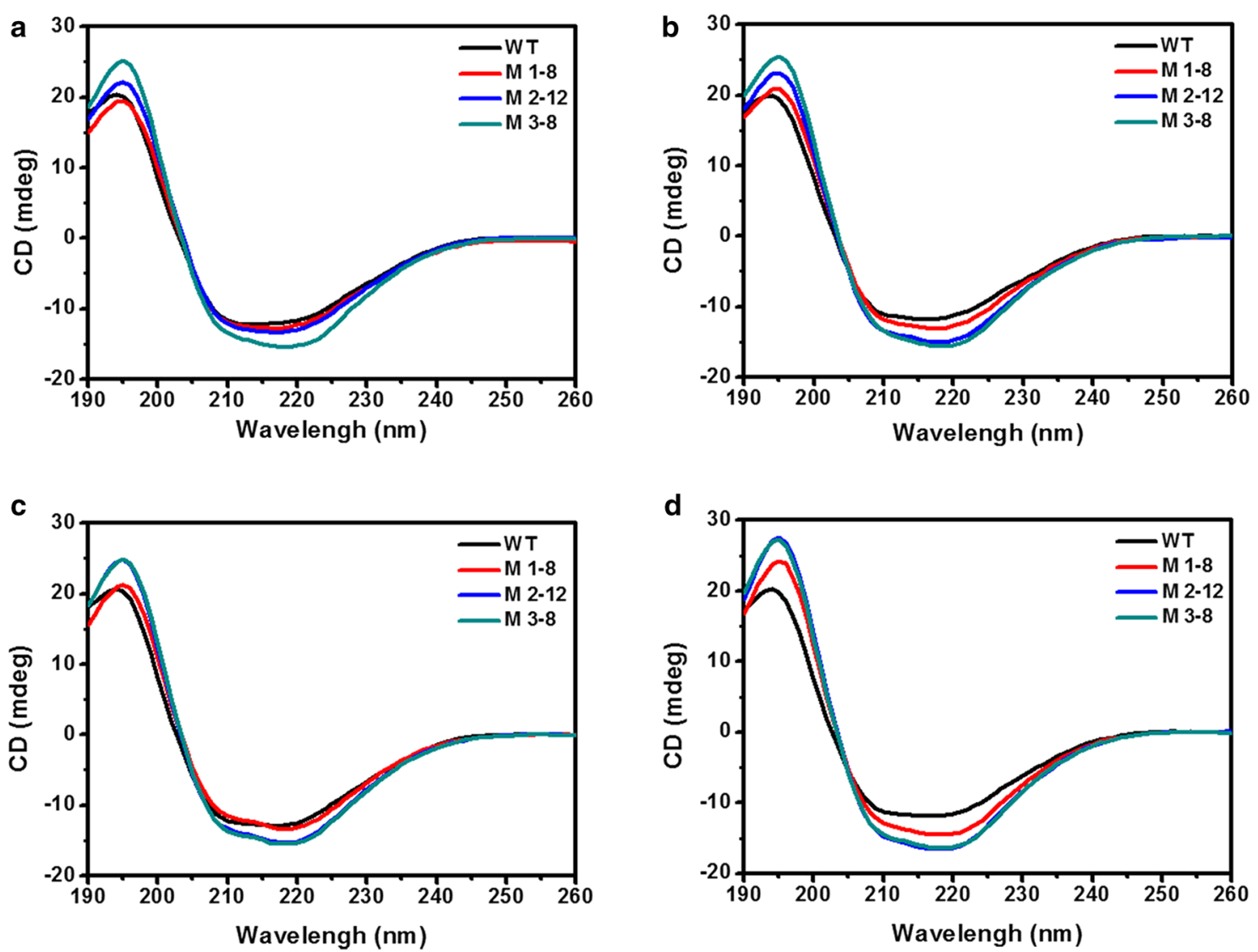

Fig. 4 Circular dichroism spectra of GsDI wild type and the mutants at a pH 5.0, b pH 5.4, c pH 6.0, d pH 7.3. Black line: WT; red line: mutant 1-8; blue line: mutant 2-12; green line: mutant 3-8

at $\mathrm{pH} 5.4$ (Fig. 3a). The mutants could retain greater than $90 \%$ activity at $\mathrm{pH} 5.4$ for $20 \mathrm{~h}$, however the wild type lost nearly $30 \%$ of its initial activity after $20 \mathrm{~h}$. The residual activity of the wild type and mutants at $60{ }^{\circ} \mathrm{C}$ further demonstrated that the mutants maintained or had slightly less activity compared to the wild type at 


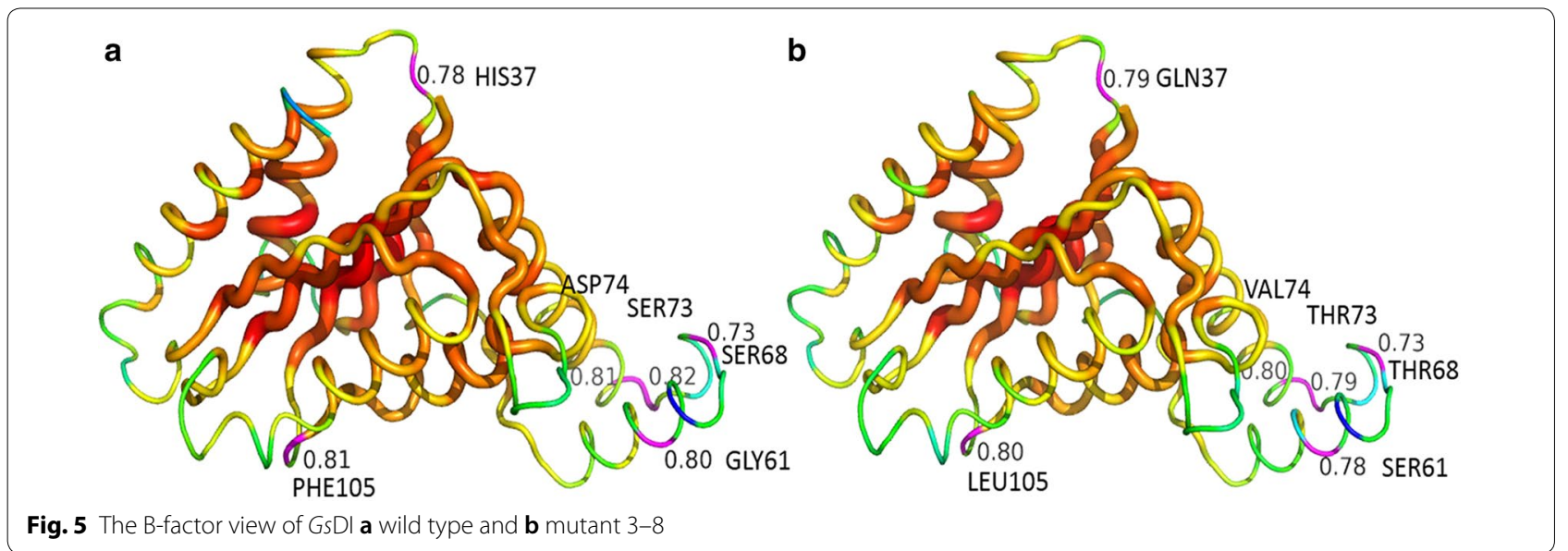

high temperatures, suggesting that the acidic tolerance improvement of the mutants had nothing to do with their thermostability (Fig. 3b). To estimate the possible misfolding or alterations in the secondary structure of the mutants, circular dichroism (CD) measurements were performed. The far-UV CD spectra of wild type and mutants are shown in Fig. 4 . The spectrum of the mutant 3-8 was different in the negative band intensity to that of the wild type at various $\mathrm{pHs}$, being decreased by 1.5 -fold. These results demonstrated that the mutants with a disruption of the protein structure might facilitate $\alpha$ helix formation and be benefit for the stability. Figure 5 is a B-factor view of wild type and mutant $3-8$, where the closer the color is to red, the larger a B-factor value is. It can be observed that the corresponding $\mathrm{B}$-factor values at the six positions are changed. The value increase indicates a theoretical benefit to the stability of the protein (Sun et al. 2019). Therefore, it can be speculated that the H37Q is likely to help the protein to maintain its activity at the acidic $\mathrm{pH}$. Since histidine is an alkaline amino acid and glutamine is a neutral one, the substitution of glutamine for histidine might influence on the electrostatic force on the protein surface (Fukunishi et al. 2012; Xiang et al. 2019).

\section{The homology model and molecular docking of mutant 3-8}

The crystal structure of Bacillus sp. FMN-dependent $\mathrm{NADH}$-azoreductase (AzrC) (PDB: 3w7a) which had $57 \%$ amino acid sequence identity was used for the threedimensional homology model and molecular docking of

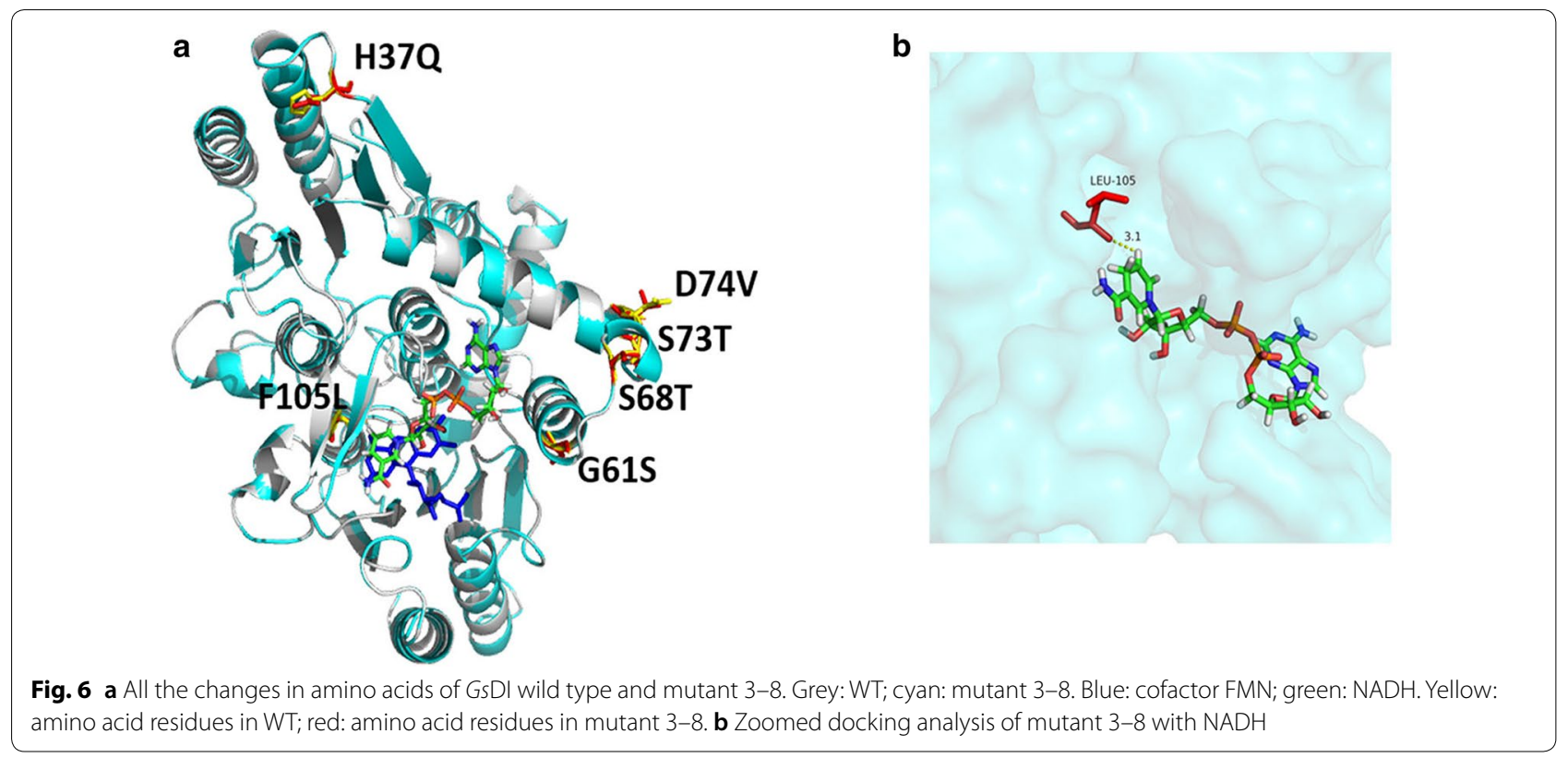


Table 4 Enzyme kinetics for GsDI wild type and mutants F105L and F105A at pH 5.4 or pH 4.5

\begin{tabular}{|c|c|c|c|c|c|c|}
\hline \multirow[t]{2}{*}{ Enzyme } & \multicolumn{3}{|l|}{ pH 5.4} & \multicolumn{3}{|l|}{$\mathrm{pH} 4.5$} \\
\hline & $K_{\mathrm{m}}(\mathrm{mM})$ & $k_{\text {cat }}\left(\mathrm{s}^{-1}\right)$ & $\begin{array}{l}k_{\text {cat }} / K_{\mathrm{m}} \\
\left(\mathrm{mM}^{-1} \mathrm{~s}^{-1}\right)\end{array}$ & $K_{\mathrm{m}}(\mathrm{mM})$ & $k_{\text {cat }}\left(\mathrm{s}^{-1}\right)$ & $\begin{array}{l}k_{\mathrm{cat}} / K_{\mathrm{m}} \\
\left(\mathrm{mM}^{-1} \mathrm{~s}^{-1}\right)\end{array}$ \\
\hline Wild type & $0.59 \pm 0.12$ & $0.18 \pm 0.04$ & $0.31 \pm 0.05$ & $1.36 \pm 0.21$ & $0.05 \pm 0.01$ & $0.04 \pm 0.01$ \\
\hline F105L & $0.31 \pm 0.07$ & $0.24 \pm 0.03$ & $0.77 \pm 0.08$ & $0.78 \pm 0.17$ & $0.13 \pm 0.02$ & $0.17 \pm 0.02$ \\
\hline F105A & $0.29 \pm 0.05$ & $0.26 \pm 0.05$ & $0.89 \pm 0.12$ & $0.66 \pm 0.13$ & $0.14 \pm 0.02$ & $0.21 \pm 0.02$ \\
\hline
\end{tabular}

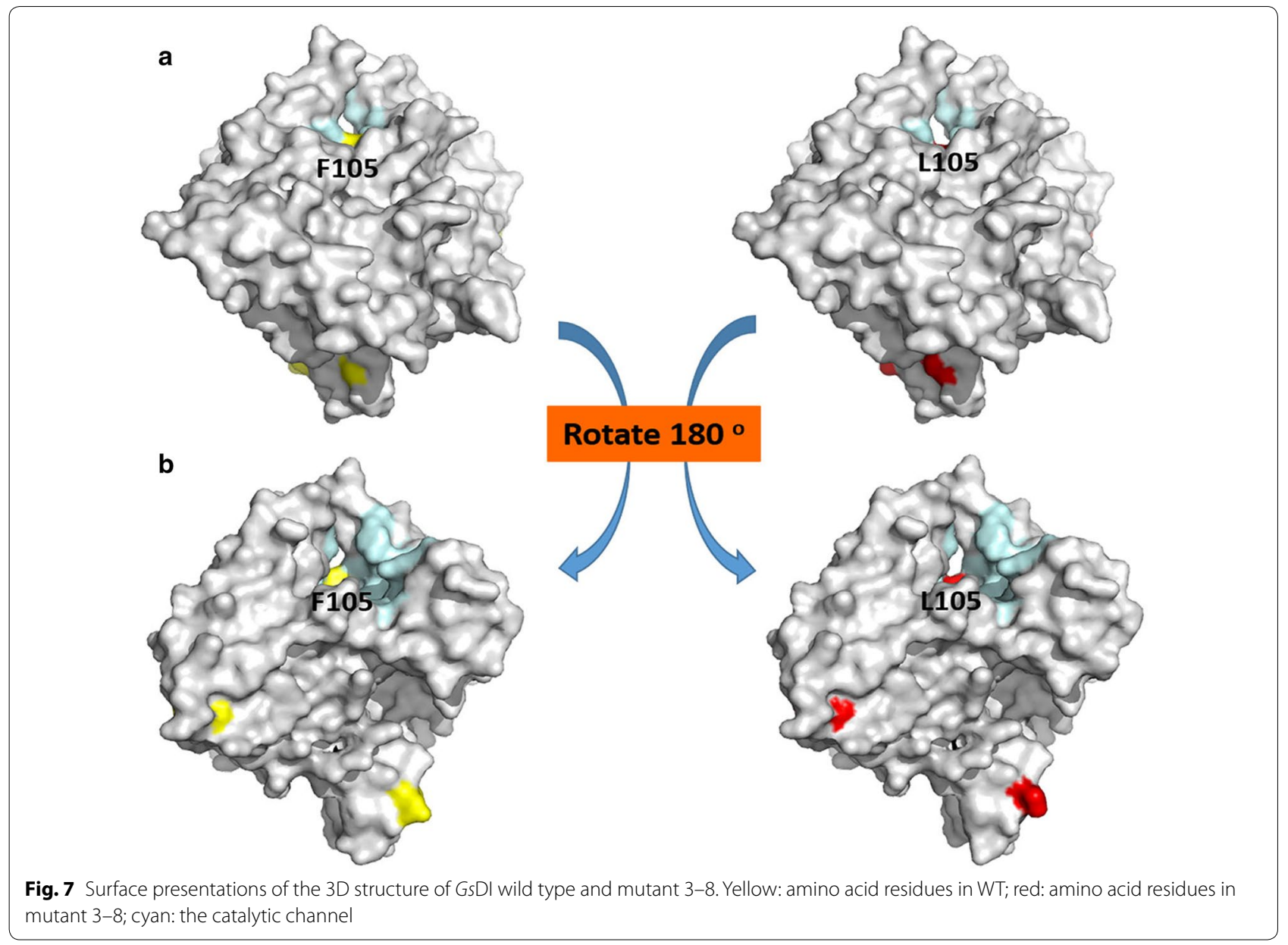

mutant 3-8. In this paper, the crystal structure of AzrC complexed with FMN and three different analogue of $\mathrm{NAD}(\mathrm{P}) \mathrm{H}$ were determined. A $\mathrm{NAD}(\mathrm{P}) \mathrm{H}$ analogue containing a triple ring which mimics the nicotinamide adenine, was sandwiched by Tyr127 (a conserved residue) and FMN, in the opposite direction to the isoalloxazine ring of FMN (Yu et al. 2014). The same result was found in our docking structure, as one mutant site, F105L, was located within $3.1 \AA$ around the activity pocket, while other mutated residues were far away (Fig. 6). This finding also agreed with the reverse mutation result mentioned above, that F105L had the greatest impact on the enzyme activity. Obtained from the site-saturation mutagenesis of F105, the F105A exhibited similar kinetics data with F105L at pH 4.5 or 5.4 (Table 4). Their binding constants were much smaller than that of the wild type. Therefore, it can be speculated that the F105L mutation allowed for less steric hindrance of a smaller amino acid leucine and made the substrate easier to be combined (Yu et al. 2014, 2019). Based on Fig. 7, it clearly presents that the catalytic channel in mutant 3-8 became larger compared to that of wild type, which would be beneficial for the substrate access and metabolite release. These factors may contribute to the increase in the specific activity of mutant 3-8. 

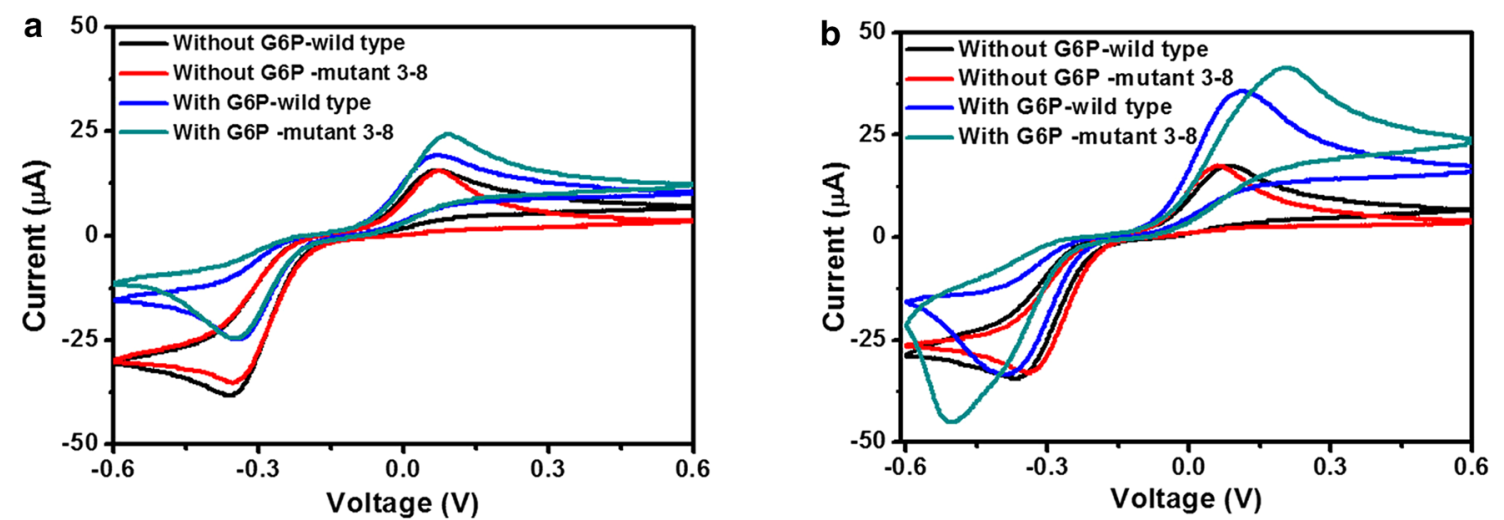

Fig. 8 The CV curves of DI and VK ${ }_{3}$-mediated EBFCs. a $0.1 \mathrm{mg}$ GsDI wild type and mutant 3-8. b $0.5 \mathrm{mg}$ GsDI wild type and mutant 3-8. Blank or red line: with GsDI wild type or mutant 3-8, without G6P; blue or green line: with same loading of GsDI wild type or mutant 3-8, with 20 mM G6P. 5 U $\mathrm{G} 6 \mathrm{PDH}$ and $5 \mathrm{U} 6 \mathrm{PGDH}$ were added. The experiment was performed at a scan rate of $10 \mathrm{mV} / \mathrm{s}$ using a three-electrode system

In comparison with F105L, G61S, S68T, D74V present slight influence on the stability, while H37Q and S73T are nonsense (Table 3). It is shown that residues G61S, S68T, D74V are closer to the activity pocket (Fig. 6a). Among them, residue G61S is located on alpha helix near the activity pocket and the change from glycine to more hydrophilic serine may benefit the water-soluble substrate reaction. Moreover, in addition to forming hydrogen bonds with F57 and S65, S61 also forms an additional hydrogen bond with F57 in mutant 3-8. The S68T and D74V located in a flexible motif adjacent to the a-helix mentioned above may contribute to more rationalized change of the activity pocket. However, the mechanism that how these residues affect the enzymatic activity and stability remains unclear and requires further efforts.

\section{EBFC performance}

In this work, the characterization of an anodic compartment containing DI and other components was evaluated. Since $\mathrm{pH} 4.5$ was too harsh for the protein, the electrochemical test was conducted at $\mathrm{pH}$ 5.4. The $\mathrm{CV}$ results without or with the substrate G6P suggested that the oxidation potential of $\mathrm{VK}_{3}$ was shifted slightly to a more positive potential, which can be expected as the mediation of $\mathrm{VK}_{3}$ was a proton-coupled electron transfer process. For the wild type or mutant $3-8$, with the increase of the amount of GsDI, the oxidation peak showed a significant improvement, indicating that this enzyme played an essential role in the redox process (Fig. 8). The higher oxidation peak height of mutant 3-8 from the $\mathrm{CV}$ plot indicated that the activity of the mutant 3-8 was better than the wild type. When $0.1 \mathrm{mg}$ of protein was added, the current of wild type was increased by $4 \mu \mathrm{A}$ compared to that without substrate G6P, and the mutant 3-8 was increased by $9 \mu \mathrm{A}, 2.3$ times higher compared to that of the wild type (Fig. 8a). When the $0.5 \mathrm{mg}$ protein was supplemented under the same condition, the current values of wild type and mutant 3-8 were significantly improved, reaching about $40 \mu \mathrm{A}$ (Fig. 8b). These results suggested that this engineered GsDI could be a potential candidate for a powerful EBFC.

\section{Conclusion}

In conclusion, directed evolution was applied to significantly increase the activity and stability of a GsDI in order to run the EBFC at lowered pHs. After three rounds of screening, the best GsDI mutant 3-8 exhibited a 4- or 7-fold increase in the catalytic activity at $\mathrm{pH}$ 5.4 or 4.5 compared to that of the wild type. The EBFC anode equipped with $0.5 \mathrm{mg}$ of mutant 3-8 achieved a maximum current of $40 \mu \mathrm{A}$ at $\mathrm{pH}$ 5.4, more than 1.3fold that with the same loading of the wild type enzyme. This study demonstrates that directed evolution is a useful strategy for improving the activity and stability of an enzyme and can be used to construct high-performance EBFCs mediated with engineered enzyme mutants.

\section{Abbreviations}

DI: Diaphorase; EBFC: Enzymatic biofuel cells; TNBT:Tetra-nitro blue tetrazolium; VK :Vitamin $\mathrm{K}_{3}$; IPTG: Isopropyl- $\beta$-D-thiogalactopyranoside; OD: Optical density; PCR: Polymerase chain reaction; SDS: Sodium dodecyl sulfate; PAGE: Polyacrylamide gel electrophoresis; POE-PCR: Prolonged overlap extension PCR; BSA: Bovine serum albumin; $\operatorname{NAD}(P)^{+}$: Nicotinamide adenine dinucleotide phosphate; G6P: Glucose 6-phosphate; G6PDH: G6P dehydrogenase; 6PGDH: 6-Phosphogluconate dehydrogenase; WT: Wild type.

\section{Acknowledgements}

We thank Dr. Zepeng Kang and Dr. Ranran Wu for the critical reading and suggestions of the manuscript and Ruimeng Gu for the help in the circular dichroism experiment.

\section{Authors' contributions}

CM and ML performed the experiments. CY and ZZ conceived the idea and supervised the research. CM and ZZ wrote and revised the manuscript. All authors read and approved the final manuscript. 


\section{Funding}

This study was supported by National Natural Science Foundation of China (21878324) to ZZ and (21778073) to CY, and the CAS Pioneer Hundred Talent Program (Type C, reference\# 2016-081) to ZZ.

\section{Availability of data and materials}

The datasets supporting this article are included in the manuscript.

\section{Ethical approval and consent to participate}

Not applicable.

\section{Consent for publication}

All of the authors have read and approved to submit it to Bioresources and Bioprocessing.

\section{Competing interests}

The authors declare that they have no competing interests.

\section{Author details}

${ }^{1}$ Tianjin Institute of Industrial Biotechnology, Chinese Academy of Sciences, 32 West 7th Avenue, Tianjin Airport Economic Area, Tianjin 300308, People's Republic of China. ${ }^{2}$ University of Chinese Academy of Sciences, 19A Yuquan Road, Shijingshan District, Beijing 100049, People's Republic of China.

Received: 13 January 2020 Accepted: 19 April 2020

Published online: 24 April 2020

\section{References}

Barton SC, Gallaway J, Atanassov P (2004) Enzymatic biofuel cells for implantable and microscale devices. Chem Rev 104:4867-4886

Bergsma J, Van Dongen MB, Konings WN (1982) Purification and characterization of NADH dehydrogenase from Bacillus subtilis. Eur J Biochem 128:151-157

Camarero S, Pardo I, Canas Al, Molina P, Record E, Martinez AT, Martinez MJ, Alcalde M (2012) Engineering platforms for directed evolution of Laccase from Pycnoporus cinnabarinus. Appl Environ Microbiol 78:1370-1384

Campbell E, Meredith M, Minteer SD, Banta S (2012) Enzymatic biofuel cells utilizing a biomimetic cofactor. Chem Commun (Camb) 48:1898-1900

Chen H, Zhu ZG, Huang R, Zhang Y-HP (2016) Coenzyme engineering of a hyperthermophilic 6-phosphogluconate dehydrogenase from NADP(+) to $N A D(+)$ with its application to biobatteries. Sci Rep 6:36311

Collins J, Zhang T, Huston S, Sun F, Zhang YH, Fu J (2016) A hidden transhydrogen activity of a FMN-bound diaphorase under anaerobic conditions. PLOS ONE 11:e0154865

Davis F, Higson SPJ (2007) Biofuel cells—recent advances and applications. Biosens Bioelectron 22:1224-1235

Deimann W, Freeman R, Fahimi HD (1981) Improved contrast in cytochemistry of dehydrogenases by scanning transmission electron microscopy. J Histochem Cytochem 29:678-681

Denard CA, Ren H, Zhao H (2015) Improving and repurposing biocatalysts via directed evolution. Curr Opin Chem Biol 25:55-64

Fukunishi H, Shimada J, Shiraishi K (2012) Antigen-antibody interactions and structural flexibility of a femtomolar-affinity antibody. Biochem 51:2597-2605

Gai P, Ji Y, Chen Y, Zhu C, Zhang J, Zhu JJ (2015) A nitrogen-doped graphene/ gold nanoparticle/formate dehydrogenase bioanode for high power output membrane-less formic acid/O2 biofuel cells. Analyst 140:1822-1826

Kaewarsa P, Laiwattanapaisal W, Palasuwan A, Palasuwan D (2017) A new paper-based analytical device for detection of glucose-6-phosphate dehydrogenase deficiency. Talanta 164:534-539

Kang ZP, Zhang Y-HP, Zhu ZG (2019) A shriveled rectangular carbon tube with the concave surface for high-performance enzymatic glucose/O2 biofuel cells. Biosens Bioelectron 132:76-83

Kim DM, Kim MY, Reddy SS, Cho J, Cho CH, Jung S, Shim YB (2013) Electrontransfer mediator for a NAD-glucose dehydrogenase-based glucose sensor. Anal Chem 85:11643-11649

Kim EJ, Kim JE, Zhang Y-HP (2018) Ultra-rapid rates of water splitting for biohydrogen gas production through in vitro artificial enzymatic pathways. Energy Environ Sci 11:2064-2072
Liang B, Li L, Mascin M, Liu A (2012) Construction of xylose dehydrogenase displayed on the surface of bacteria using ice nucleation protein for sensitive D-xylose detection. Anal Chem 84:275-282

Ma CL, Wu RR, Huang R, Jiang WX, You C, Zhu LL, Zhu ZG (2019) Directed evolution of a 6-phosphogluconate dehydrogenase for operating an enzymatic fuel cell at lowered anodic pHs. J Electroanal Chem 851:113444

Mano N (2019) Engineering glucose oxidase for bioelectrochemical applications. Bioelectrochemistry 128:218-240

Mano N, Mao F, Heller A (2003) Characteristics of a miniature compartmentless glucose-O2 biofuel cell and its operation in a living plant. J Am Chem Soc 125:6588-6594

Matsumoto K, Mukai Y, Ogata D, Shozui F, Nduko JM, Taguchi S, Ooi T (2010) Characterization of thermostable FMN-dependent NADH azoreductase from the moderate thermophile Geobacillus stearothermophilus. Appl Microbiol Biotechnol 86:1431-1438

Monza E, Lucas MF, Camarero S, Alejaldre LC, Martinez AT, Guallar V (2015) Insights into laccase engineering from molecular simulations: toward a binding-focused strategy. J Phys Chem Lett 6:1447-1453

Novoa C, Dhoke GV, Mate DM, Martinez R, Haarmann T, Schreiter M, Eidner J, Schwerdtfeger R, Lorenz P, Davari MD, Jakob F, Schwaneberg U (2019) KnowVolution of a fungal laccase toward alkaline $\mathrm{pH}$. ChemBioChem 20:1458-1466

Rice L, Phoenix DA, Wainwright M, Waring JJ (1998) Effect of increasing methylation on the ability of methylene blue to cause diaphorase-catalysed oxidation of NADH. Biochem Soc Trans 26:S319

Sakai H, Nakagawa T, Tokita Y, Hatazawa T, Ikeda T, Tsujimura S, Kano K (2009) A high-power glucose/oxygen biofuel cell operating under quiescent conditions. Energy Environ Sci 2:133-138

Scheiblbrandner S, Ludwig R (2019) Cellobiose dehydrogenase: bioelectrochemical insights and applications. Bioelectrochemistry 131:107345

Shen X, Bao W, Yu W, Liang R, Nguyen B, Liu Y (2017) An improved method with high sensitivity and low background in detecting low beta-galactosidase expression in mouse embryos. PLoS ONE 12:e0176915

Shoji K, Akiyama Y, Suzuki M, Nakamura N, Ohno H, Morishima K (2016) Biofuel cell backpacked insect and its application to wireless sensing. Biosens Bioelectron 78:390-395

Sugiyama T, Goto Y, Matsumoto R, Sakai H, Tokita Y, Hatazawa T (2010) A mediator-adapted diaphorase variant for a glucose dehydrogenasediaphorase biocatalytic system. Biosens Bioelectron 26:452-457

Sun Z, Liu Q, Qu G, Feng Y, Reetz MT (2019) Utility of B-factors in protein science: interpreting rigidity, flexibility, and internal motion and engineering thermostability. Chem Rev 119:1626-1665

Wu RR, Ma CL, Zhang Y-HP, Zhu ZG (2018) Complete oxidation of xylose for bioelectricity generation by reconstructing a bacterial xylose utilization pathway in vitro. ChemCatChem 10:2030-2035

Xiang L, Lu YH, Wang H, Wang MX, Zhang GM (2019) Improving the specific activity and pH stability of xylanase XynHBN188A by directed evolution. Bioresour Bioprocess 6:25

Xiao XX, Xia HQ, Wu RR, Bai L, Yan L, Magner E, Cosnier S, Lojou E, Zhu ZG, Liu A (2019) Tackling the challenges of enzymatic (bio) fuel cells. Chem Rev 119:9509-9558

Yang KK, Wu Z, Arnold FH (2019) Machine-learning-guided directed evolution for protein engineering. Nat Methods 16:687-694

You C, Zhang XZ, Zhang Y-HP (2012) Simple cloning via direct transformation of PCR product (DNA multimer) to Escherichia coli and Bacillus subtilis. Appl Environ Microbiol 78:1593-1595

Yu EH, Prodanovic R, Guven G, Ostafe R, Schwaneberg U (2011) Electrochemical oxidation of glucose using mutant glucose oxidase from directed protein evolution for biosensor and biofuel cell applications. Appl Biochem Biotechnol 165:1448-1457

Yu J, Ogata D, Gai ZQ, Taguchi S, Tanaka I, Ooi T, Yao M (2014) Structures of AzrA and of AzrC complexed with substrate or inhibitor: insight into substrate specificity and catalytic mechanism. Acta Crystallogr D Biol Crystallogr 70:553-564

Yu SS, Yao PY, Li JL, Feng JH, Wu QQ, Zhu DM (2019) Improving the catalytic efficiency and stereoselectivity of a nitrilase from Synechocystis sp. PCC6803 by semi-rational engineering en route to chiral $\gamma$-amino acids. Catal Sci Technol 9:1504-1510

Zhu ZG, Zhang Y-HP (2017) In vitro metabolic engineering of bioelectricity generation by the complete oxidation of glucose. Metab Eng 39:110-116 
Zhu ZW, Wang M, Gautam A, Nazor J, Momeu C, Prodanovic R, Schwaneberg U (2007) Directed evolution of glucose oxidase from Aspergillus niger for ferrocenemethanol-mediated electron transfer. Biotechnol J 2:241-248 Zhu ZG, Kin Tam T, Sun FF, You C, Zhang Y-HP (2014) A high-energy-density sugar biobattery based on a synthetic enzymatic pathway. Nat Commun 5:3026

\section{Publisher's Note}

Springer Nature remains neutral with regard to jurisdictional claims in published maps and institutional affiliations.

\section{Submit your manuscript to a SpringerOpen ${ }^{\odot}$ journal and benefit from:}

- Convenient online submission

- Rigorous peer review

- Open access: articles freely available online

- High visibility within the field

- Retaining the copyright to your article

Submit your next manuscript at $\boldsymbol{\nabla}$ springeropen.com 